\title{
Avaliação da atividade antibacteriana, citotóxica e antioxidante da espécie vegetal Opuntia cochenillifera (L.) Mill
}

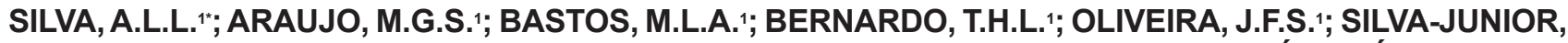
E.F.2; SANTOS-JUNIOR, P.F.S.2; ARAUJO, M.V.; ALEXANDRE-MOREIRA, M.S. ; ARAÚJO-JÚNIOR, J.X.2; VERISSIMO, R.C.S.S. ${ }^{1}$

1Universidade Federal de Alagoas, Laboratório de Pesquisa em Tratamento de Feridas (LpTF), Av. Lourival Melo Mota, s/n, Tabuleiro dos Martins, 57072-900, Maceió - AL. 2Universidade Federal de Alagoas, Laboratório de Química Medicinal (LQM), Av. Lourival Melo Mota, s/n, Tabuleiro dos Martins, 57072-900, Maceió - AL. ${ }_{3}^{3}$ Universidade Federal de Alagoas, Laboratório de Farmacologia e Imunidade (LAFI), Av. Lourival Melo Mota, s/n, Tabuleiro dos Martins, 57072-900, Maceió - AL. *Autor para correspondência: le_lopess@hotmail.com
\end{abstract}

RESUMO: O presente estudo teve como objetivo avaliar a atividade antibacteriana, antioxidante e citotóxica da espécie Opuntia cochenillifera (L.) Mill. Foi realizada a prospecção fitoquímica e espectroscopia de absorção de infravermelho (IV) dos extratos etanólicos brutos e frações dos cladódios grande e pequeno. A atividade antioxidante foi avaliada pelo método da capacidade sequestradora de radicais livres utilizando o radical sintético 2,2-difenil-1-picrilhidrazila (DPPH). A atividade citotóxica foi obtida através do método colorimétrico do Metiltetrazolium (MTT). Já a atividade antibacteriana foi avaliada pelo método de microdiluição em caldo para determinar a concentração inibitória mínima (CIM) frente às estirpes bacterianas Staphylococcus aureus, Staphylococcus epidermidis, Pseudomonas aeruginosa e Escherichia coli. A prospecção fitoquímica revelou principalmente a presença de fenóis, esteroides livres, alcaloides, alcanos, além de outras classes químicas. O IV apresentou grupos funcionais como alcanos, carbonilas, grupos de metila, duplas ligações de carbono, grupamentos alquilamina, entre outros. Sobre a citotoxicidade na concentração de $100 \mu \mathrm{g} / \mathrm{mL}$, os dois extratos brutos, todas as frações do cladódio grande e as frações de clorofórmio e metanol do cladódio pequeno não apresentaram toxicidade. Os extratos brutos e frações do cladódio grande e pequeno, não demonstraram atividade antibacteriana e nem antioxidante. Esses resultados podem fornecer suporte para pesquisas futuras, visando outras atividades biológicas da presente espécie vegetal.

Palavras-chave: Opuntia cochenillifera (L.) Mill. Composição química. Atividade antibacteriana. Atividade citotóxica. Antioxidante.

\begin{abstract}
Evaluation of antibacterial, cytotoxic, and antioxidant activity of the plant species Opuntia cochenillifera (L.) Mill. The purpose of this study was to evaluate the antibacterial, antioxidant, and cytotoxic activity of Opuntia cochenillifera (L.) Mill. A phytochemical screening and infrared (IR) absorption spectroscopy were performed in the crude ethanolic extracts and fractions of large and small cladodes. The antioxidant activity was evaluated through the qualitative method of free-radical scavenging capacity using the synthetic radical 2,2-diphenyl-1-picrylhydrazyl (DPPH). The cytotoxic activity was obtained by the cell viability assay using methyl thiazolyl tetrazolium (MTT). Antibacterial activity was evaluated by broth microdilution method to determine the minimum inhibitory concentration (MIC) against the bacterial strains Staphylococcus aureus, Staphylococcus epidermidis, Pseudomonas aeruginosa, and Escherichia coli. The phytochemical screening mainly revealed the presence of phenols, flavonoids, free steroids, alkaloids, alkanes, and other chemical classes.

The IR spectroscopy presented functional groups such as alkanes, carbonyls, methyl groups, carbon double bonds, and alkylamino groups, among others. Regarding cytotoxicity in the concentration of $100 \mu \mathrm{g} / \mathrm{mL}$, neither the crude extracts, the fractions of the large cladode, nor the chloroform and methanol fractions of small cladode presented toxicity. The crude ethanolic extracts and fractions of large and small cladode showed no antibacterial or antioxidant activity. These results may provide support for future research aimed at other biological activities of this plant species.
\end{abstract}

Keywords: Opuntia cochenillifera (L.) Mill., chemical composition, antibacterial activity, cytotoxic activity, antioxidant.

Recebido para publicação em 20/07/2015

Aceito para publicação em 27/01/2016

10.1590/1983-084X/15_145

Rev. Bras. PI. Med., Campinas, v.18, n.1, supl. I, p.307-315, 2016. 


\section{INTRODUÇÃO}

O tratamento de feridas é algo antigo na sociedade (Gomes \& Carvalho 2002), em especial o de feridas infectadas, é muito presente na área de saúde, já que o uso indiscriminado de antibióticos faz com que as bactérias acabem se adaptando e adquirindo resistência aos agentes antimicrobianos (Santos, 2004).

É notória a necessidade de um produto que apresente capacidade de cicatrização ao mesmo tempo em que iniba o desenvolvimento de microrganismos sem causar resistência bacteriana com o mínimo de danos possíveis ao organismo. Agentes antioxidantes podem ser substâncias que reúnam estas características, tendo em vista sua capacidade de promover neovascularização e interferir positivamente na cicatrização de feridas (Pace et al., 2006).

A biodiversidade brasileira é notória, já que o país possui a maior flora do mundo, sendo responsável por mais de $20 \%$ do total de espécies vegetais do planeta (Lewinsohon \& Prado, 2003). As plantas constituem ainda, uma importante fonte de obtenção de medicamentos, sendo $48 \%$ advindos de produtos naturais (Balunas \& Kinghorn, 2005).

A caatinga é hoje um bioma muito ameaçado. Único do Brasil, esse bioma possui espécies vegetais endêmicas, principalmente da família Cactaceae, com significativos potenciais biológicos (Taylor \& Zappi, 2002).

Um dos gêneros mais presente no Brasil, especificamente no Nordeste é o Opuntia spp., conhecido popularmente como Palma Forrageira. A diversidade de usos e aplicações da palma e sua versatilidade, ainda precisa ser melhor estudada (Chiacchio et al., 2006).

A palma é utilizada na alimentação humana e animal (Nunes, 2011). Estudos etnobotânicos remetem o uso da mesma no tratamento de queimaduras, ressecamento, inflamação, infecção urinária, gripe, problemas nos rins, dor abdominal, reumatismo, problemas na uretra e disenteria (Lewis, 2003; Barbera et al., 1999; Guerreiro et al., 2000). Andrade et al. (2006) relata que no semiárido do estado de Alagoas e Pernambuco ela vem sendo utilizada para o tratamento de tumores.

Estudos realizados com o gênero Opuntia comprovam a atividade cicatrizante (Park \& Chun, 2001; Galati et al., 2003; Trombetta et al., 2006; Ammar et al., 2015), antioxidante (Butera et al., 2002; Semedo, 2012; Madrigal-Santillán et al., 2013), antinflamatória (Arauza, 2009; Galati et al., 2003) e antitumoral (Zou et al., 2005; Hahm et al., 2010; Poejo, 2011).

Diante da importância que essa espécie vegetal tem, e com pesquisas restritas sobre as propriedades farmacológicas das plantas da caatinga, o presente estudo teve como objetivo a avaliação da atividade antibacteriana, citotóxica e antioxidante da espécie Opuntia cochenillifera (L.) Mill.

\section{MATERIAL E MÉTODO \\ Material botânico}

A espécie vegetal foi coletada na região da Caatinga, no município de Olho DıÁgua do Casado, no estado de Alagoas, Brasil $\left(09^{\circ} 29^{\prime} 21.9^{\prime \prime} \mathrm{S} / 37^{\circ}\right.$ 49' 16.9" W). A planta foi identificada pela botânica Rosângela Pereira de Lyra Lemos e depositada no herbário do Instituto de Meio Ambiente de Alagoas (IMA) com a exsicata de número 57.924.

\section{Extração}

O material vegetal coletado, devido a sua grande quantidade de água, foi desidratado em uma estufa de secagem com circulação de ar a $40^{\circ} \mathrm{C}$ por 72 horas. Foi triturado e extraído por maceração utilizando etanol a $96^{\circ}$, realizada em três ciclos de 72 h cada. O macerado obtido foi filtrado e concentrado em evaporador rotativo sob pressão reduzida.

Foram coletadas alíquotas de $18 \mathrm{~g}$ dos extratos brutos ainda úmidos e, posteriormente, realizada filtração em coluna cromatográfica, empregando-se sílica gel mesh 60 Merck ${ }^{\circledR}$ como fase estacionária e, como fases móveis, hexano, clorofórmio, acetato de etila e metanol, todos em grau absoluto.

O processo de filtração foi monitorado utilizando-se a técnica de cromatografia em camada delgada (CCD), onde apenas foi permitido o aumento da polaridade após a completa extração pela fase móvel, seguindo-se a ordem supracitada. As frações provenientes de cada fase móvel, num total de quatro, foram coletadas e secas sob pressão reduzida em evaporador rotativo.

\section{Prospecção fitoquímica}

A prospecção fitoquímica dos extratos foi realizada de acordo com o protocolo descrito por Matos (2009), empregando-se cloreto férrico para fenóis e taninos; variação de $\mathrm{pH}$ (valores entre 3-12) para antocianinas, flavonoides, antocianidinas, leucoantocianidinas, catequinas, flavanonas, flavonóis, flavanonóis e xantonas; reagente de Liebermann-Buchard para esteroides e triterpenos; agitação mecânica para saponinas; reagente de Dragendorff para alcaloides; e solução de $\mathrm{KOH}$ a $10 \%$ para antraquinonas, antronas e cumarinas, esta última, seguida de leitura em luz ultravioleta (UV) em comprimento

Rev. Bras. PI. Med., Campinas, v.18, n.1, supl. I, p.307-315, 2016. 
de onda fixo em 365 nanômetros.

Espectroscopia de absorção de Infravermelho (IV)

Os espectros de infravermelho foram coletados em um espectrômetro Thermo Scientific, modelo Nicolet iS10, em modo Smart OmniSampler Infrared Fourier Transform Spectroscopy (SOSIFT), com acessório de Refletância Total Atenuada (RTA), com um cristal de germânio. Os espectros foram adquiridos em 32 escâneres em resolução de $100 \mathrm{~cm}^{-1}$, na região entre 4000 e $700 \mathrm{~cm}^{-1}$.

\section{Avaliação da atividade sequestradora de radicais livres}

A avaliação qualitativa da atividade antioxidante ocorreu por meio do radical sintético 2,2-difenil-1-picrilhidrazila (DPPH), que se baseia na capacidade de reação do radical sintético com substâncias doadoras de hidrogênio $(H)$. Foram preparadas alíquotas contendo os extratos etanólicos brutos da espécie vegetal Opuntia cochenillifera (L.) Mill para posterior preparação das cromatoplacas. Após a preparação, foi utilizado o padrão positivo $(+)$ catequina $(1 \mathrm{mg} /$ $\mathrm{mL}$ em metanol) e a cromatoplaca foi imergida por 10 segundos em solução metanólica 0,4 $\mu \mathrm{M}$ do DPPH. Em seguida, as cromatoplacas foram secas à temperatura ambiente, a atividade antioxidante é sugerida quando nos Fatores de Retenção, aparecem manchas amareladas sob o fundo roxo, resultantes da redução do DPPH, quando comparadas com o padrão positivo (Brand-Williams et al., 1995).

Ensaio de viabilidade celular através do teste colorimétrico do Metiltetrazolium (MTT)

Os macrófagos da linhagem J774 foram colocados em placas de 96 poços com a densidade de $2 \times 10^{5}$, por poços cultivados com o meio Dulbecco Mem (DMEM) suplementado com $10 \%$ de soro fetal bovino, onde cada cavidade foi preenchida com $200 \mu \mathrm{L}$ do meio das células. Os extratos e frações dos cladódios grande e pequeno, foram usados para tratar as células na concentração de $100 \mu \mathrm{g} / \mathrm{mL}$ por 48 h e após, foram levados à estufa a $5 \%$ de $\mathrm{CO}_{2}$. Uma hora antes de adicionar o MTT, em três poços, as células foram lisadas com $2 \mu \mathrm{L}$ de Triton 100x para comparação da morte celular.

Como Controle Positivo foi utilizado o antibiótico Ciprofloxacino a $100 \mu \mathrm{g} / \mathrm{mL}$, e para controle negativo o dimetilsulfóxido (DMSO) a 0.1 $\%$. Após incubação total de $48 \mathrm{~h}$, o sobrenadante foi descartado e em cada cavidade foi adicionado $100 \mu \mathrm{L}$ de uma solução de MTT $(500 \mu \mathrm{g} / \mathrm{mL})$, sendo reincubadas por mais $1 \mathrm{~h}$. Passado o período, o sobrenadante foi desprezado e o precipitado ressuspendido com $100 \mu \mathrm{L}$ de DMSO. A leitura para a quantificação do sal tetrazólio reduzido a formazan foi realizada em um leitor de microplacas no comprimento de onda de $550 \mathrm{~nm}$.

A análise foi realizada por meio do teste ANOVA e Tukey e das diferenças das médias das absorbâncias entre os grupos tratados e os de controle, com nível de significância de $p<0,05$. Os dados foram apresentados como percentual de viabilidade celular que foi calculado pela fórmula a seguir:

\section{Método de microdiluição em caldo}

Os extratos e frações dos cladódios grande e pequeno da espécie Opuntia cochenillifera (L.) Mill e o antibiótico Ciprofloxacino, foram testados frente às bactérias Staphylococcus aureus (ATCC 25923), Staphylococcus epidermidis (ATCC 14990), Pseudomonas aeruginosa (ATCC 27853) e Escherichia coli (ATCC 14942). O protocolo seguido foi baseado no Clinical Laboratory Standards Institute (CLSI, 2012).

A solubilização das amostras se deu através da mistura de $5 \mathrm{mg}$ do extrato etanólico bruto e das frações da planta, adicionados a 100 $\mu \mathrm{L}$ de solução de Cremophor a $2 \%$ e diluídos em 4,9 mL de Caldo Mueller-Hinton, obtendo concentração de $1000 \mu \mathrm{g} / \mathrm{mL}$. Todos os poços da placa receberam $100 \mu \mathrm{L}$ de Caldo Mueller Hinton estéril, nas colunas de 1 a 9 da linha $A$ foram colocados $100 \mu \mathrm{L}$ das amostras. A coluna 10 foi destinada para o Controle de Crescimento, onde foi adicionado apenas o inóculo microbiano; 11 para o Controle Negativo, com Cremophor a $2 \%$ e 12 para o Controle de Esterilidade da placa (CE), onde foi utilizado apenas o Caldo Mueller-Hinton. Após esse processo, $100 \mu \mathrm{L}$ do conteúdo de cada orifício da linha $A$ onde foi homogeneizado e transferido para a linha $B$, repetindo assim o processo até a linha $\mathrm{H}$, com excesso desprezado.

As amostras de bactérias foram solubilizadas em uma solução de 1,5 x 10: UFC/ $\mathrm{mL}$, com concentração de acordo com o padrão de 0,5 da escala de McFarland, e posteriormente rediluídas numa proporção de 1:20 (v/v). Cada poço recebeu $10 \mu \mathrm{L}$ de inóculo bacteriano com concentração final de $10^{4} \mathrm{UFC} / \mathrm{mL}$. As placas com as bactérias foram armazenadas em estufa bacteriológica a $35^{\circ} \mathrm{C}$ para crescimento por $18 \mathrm{~h}$. Após este período, foram adicionados $20 \mu \mathrm{L}$ de Cloreto 2,3,5 Trifenil Tetrazolium (TTC) a $5 \%$ em cada poço, e as placas foram re-incubadas por mais $3 \mathrm{~h}$. Nos poços que apresentaram coloração avermelhada apontaram crescimento bacteriano, enquanto nos que mantiveram coloração original indicaram inibição do crescimento bacteriano.

Rev. Bras. PI. Med., Campinas, v.18, n.1, supl. I, p.307-315, 2016. 


\section{RESULTADOS}

Rendimento dos extratos brutos e frações

Os extratos brutos secos apresentaram rendimento de $\sim 11 \mathrm{~g}(61 \%)$ e $\sim 15 \mathrm{~g}$ (83 \%), cladódios grande e pequeno, respectivamente. Já para frações foram obtidos os seguintes rendimentos: $2,29 \mathrm{~g}(29 \%)$ da fração hexânica; $0,06 \mathrm{~g}(0,75 \%)$ fração clorofórmica; $1,08 \mathrm{~g} \mathrm{(13 \% )}$ fração em acetato de etila e 1,26g (15 \%) fração metanólica para o cladódio grande e, 2,8 g (35\%) fração hexânica; 0,99 g (12 \%) fração clorofórmica; $1,02(12 \%)$ fração em acetato de etila e $1,18 \mathrm{~g} \mathrm{(14}$ $\%)$ fração metanólica para o cladódio pequeno.

\section{Prospecção fitoquímica}

Através da análise fitoquímica, foi possível observar a presença dos seguintes constituintes nos cladódios grande e pequeno (Tabela 1). Pode-se notar através dos testes,

TABELA 1. Detecção de substâncias químicas presentes nos extratos etanólicos brutos dos cladódios pequeno e grande da espécie vegetal Opuntia cochenillifera (L.) Mill.

\begin{tabular}{|c|c|c|}
\hline \multicolumn{3}{|l|}{ Análise Fitoquímica } \\
\hline \multirow{3}{*}{ Classes } & \multicolumn{2}{|c|}{ Amostras } \\
\hline & Cladódio & Cladódio \\
\hline & Grande & Pequeno \\
\hline Fenóis & + & - \\
\hline Taninos & - & + \\
\hline Antocianinas & - & - \\
\hline Antocianidinas & - & - \\
\hline Flavonoides & - & + \\
\hline Leucoantocianidinas & - & - \\
\hline Catequinas & - & - \\
\hline Flavononas & - & + \\
\hline Flavonóis & - & + \\
\hline Flavanonóis & - & + \\
\hline Xantonas & - & + \\
\hline Esteroides livres & + & + \\
\hline Triterpenos & - & - \\
\hline Saponinas & - & + \\
\hline Alcaloides & + & + \\
\hline Antraquinonas & + & + \\
\hline Antronas & + & - \\
\hline Cumarinas & - & - \\
\hline
\end{tabular}

Nota: - : não há presença da substância na espécie vegetal; +: há presença da substância na espécie vegetal; que nos extratos etanólico brutos há presença significante de fenóis no cladódio grande, além de grande quantidade de esteroides livres e quantidade moderada de alcaloides em ambos os cladódios.

\section{Espectroscopia de absorção de Infravermelho (IV)}

A partir dos espectros obtidos na região do IV (Figura 1) para os extratos etanólico brutos dos cladódios grande e pequeno e nas frações, foi possível observar e confirmar a ocorrência das classes de metabólitos secundários demonstradas na prospecção fitoquímica realizada.

Nos extratos etanólicos brutos dos cladódios grande e pequeno, foi observado no IV a presença de hidroxila de álcool, ligações C-O, alcanos, carbonilas, carbono hibridizado ligado a hidrogênio, grupos de metila, duplas ligações de carbono e grupamentos alquilamina (Figura 1).

Para as frações de ambos os cladódios (Figuras 2 e 3), foi possível observar no IV os seguintes grupos funcionais: alcanos, $\mathrm{C}=\mathrm{O}, \mathrm{C}-\mathrm{O}$, carbonila, metila, alquilamina, hidroxila e $\mathrm{C}=\mathrm{C}$.

\section{Avaliação da atividade sequestradora de radicais livres \\ No presente ensaio, os extratos} etanólicos brutos não apresentaram capacidade sequestradora de radicais livres, devido ao não aparecimento da mancha amarelada sobre fundo roxo nos Fatores de Retenção, e por isso não houve o prosseguimento para o teste quantitativo.

Ensaio de viabilidade celular através do teste colorimétrico do Metiltetrazolium (MTT)

Por meio da análise das médias das absorbâncias em comparação com o controle negativo, na concentração de $100 \mu \mathrm{g} / \mathrm{mL}$, não foi observada toxicidade nos extratos etanólico brutos, sem diferença estatística entre as amostras e o controle negativo (DMSO a 0.1 $\%$ ), com um porcentual de viabilidade celular de $77,40 \%$ para o cladódio grande e 108,36 \% para o cladódio pequeno. Nas frações do cladódio grande na concentração de 100 ug/ $\mathrm{mL}$, as mesmas não se apresentaram tóxicas, já para as frações do cladódio pequeno, na mesma concentração, houve toxicidade, exceto na fração de clorofórmio com viabilidade celular de 74,01 $\%$, e na de metanol com viabilidade de $91,81 \%$. O controle positivo, Ciprofloxacino, apresentou viabilidade celular na concentração de $100 \mu \mathrm{M}$ de $97,50 \%$.

\section{Microdiluição em caldo Os extratos etanólicos brutos e as}

Rev. Bras. PI. Med., Campinas, v.18, n.1, supl. I, p.307-315, 2016. 

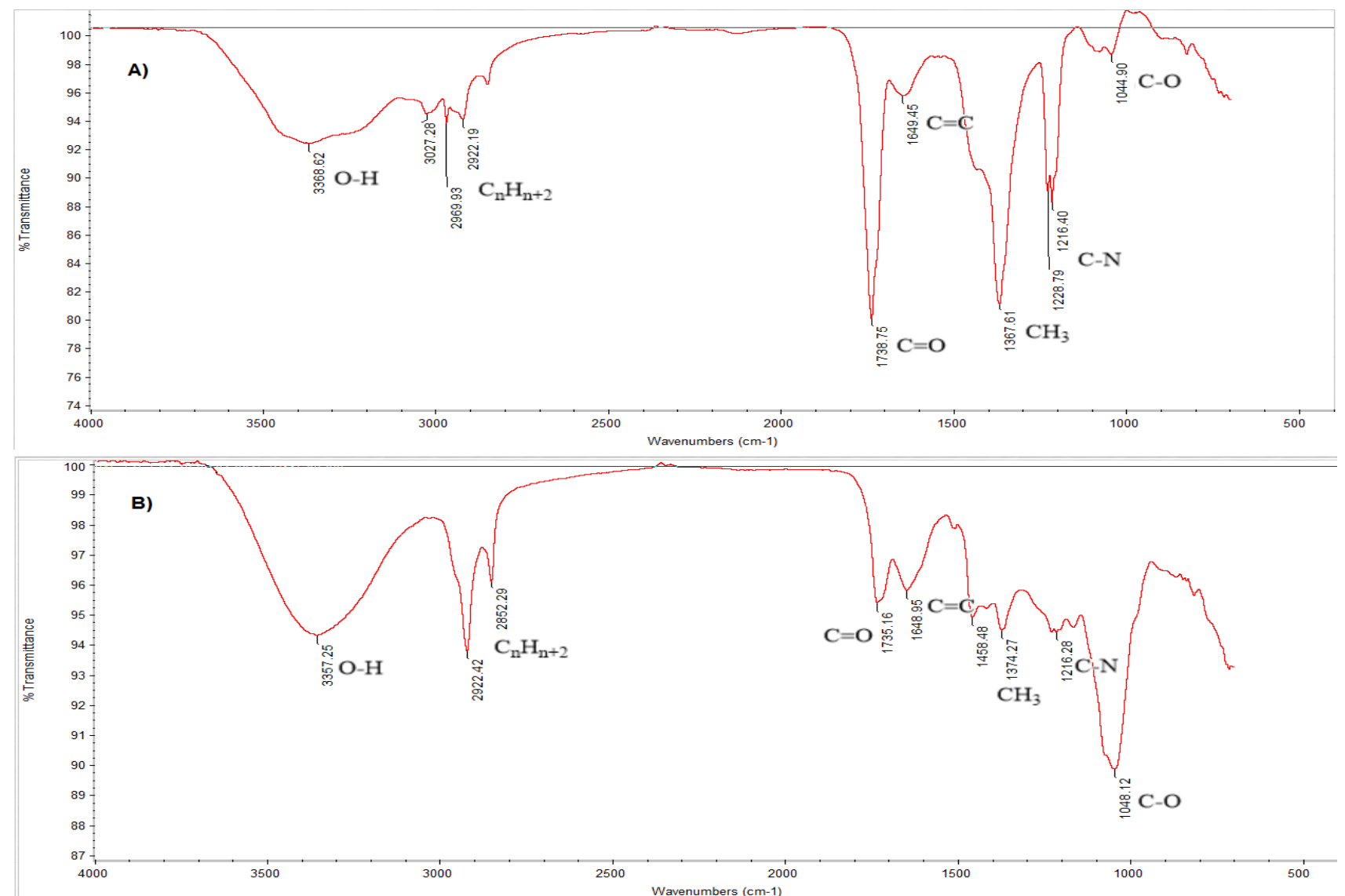

FIGURA 1. Espectro de absorção na região do infravermelho e as principais bandas e estiramentos dos extratos etanólicos brutos.

Nota: Em A, cladódio grande; Em B, cladódio pequeno. Fonte: Autora da pesquisa, 2015.
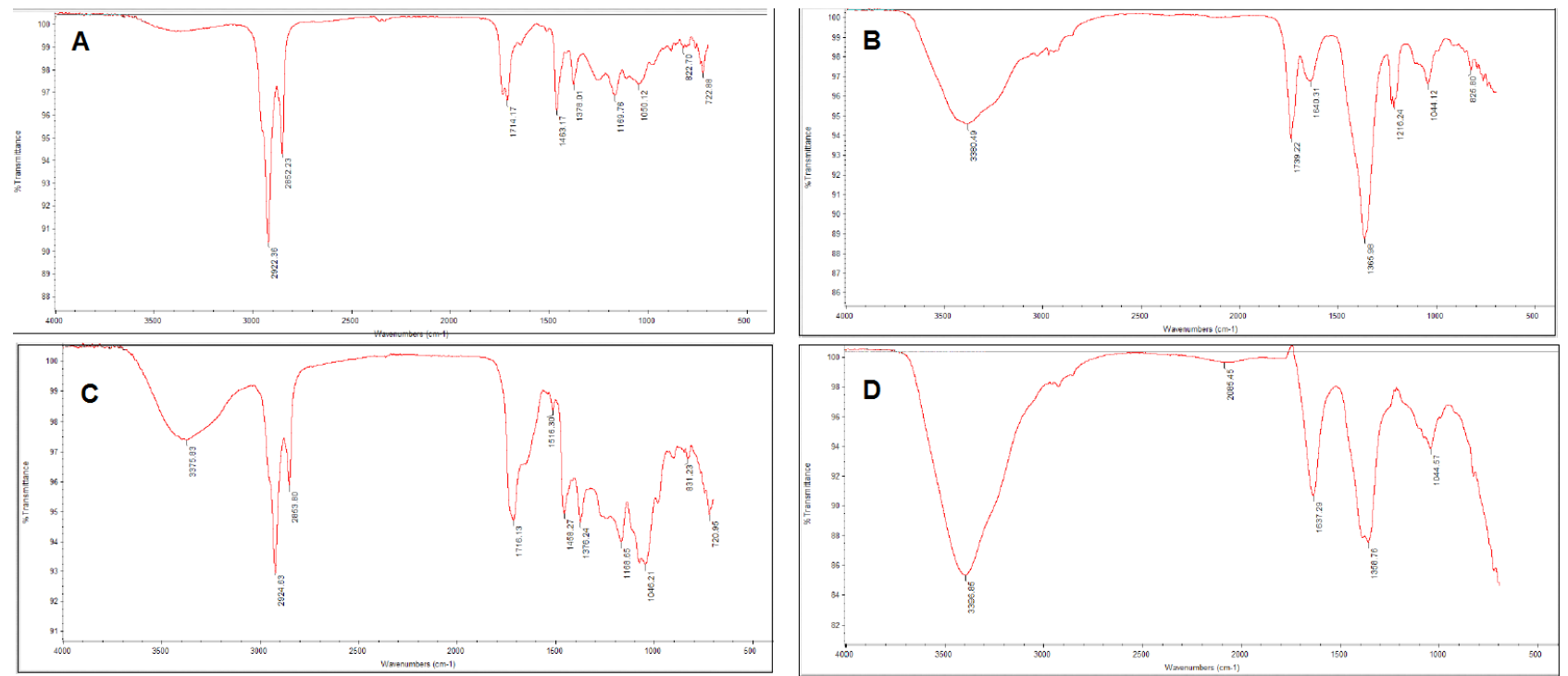

FIGURA 2. Espectro de absorção na região do infravermelho e as principais bandas e estiramentos das frações do cladódio grande.

Nota: Frações hexânica (A), clorofórmica (B), acetato de etila (C) e metanólica (D). Fonte: Autora da pesquisa, 2015.

frações de ambos os cladódios não apresentaram atividade antibacteriana frente às estirpes Staphylococcus aureus, Staphylococcus epidermidis, Pseudomonas aeruginosa e
Escherichia coli. Como controle positivo, foi utilizado o antibiótico Ciprofloxacino, que apresentou uma CIM com variação de $0.022 \mu \mathrm{g} /$ $\mathrm{mL}$ a $0.25 \mu \mathrm{g} / \mathrm{mL}$.

Rev. Bras. PI. Med., Campinas, v.18, n.1, supl. I, p.307-315, 2016. 

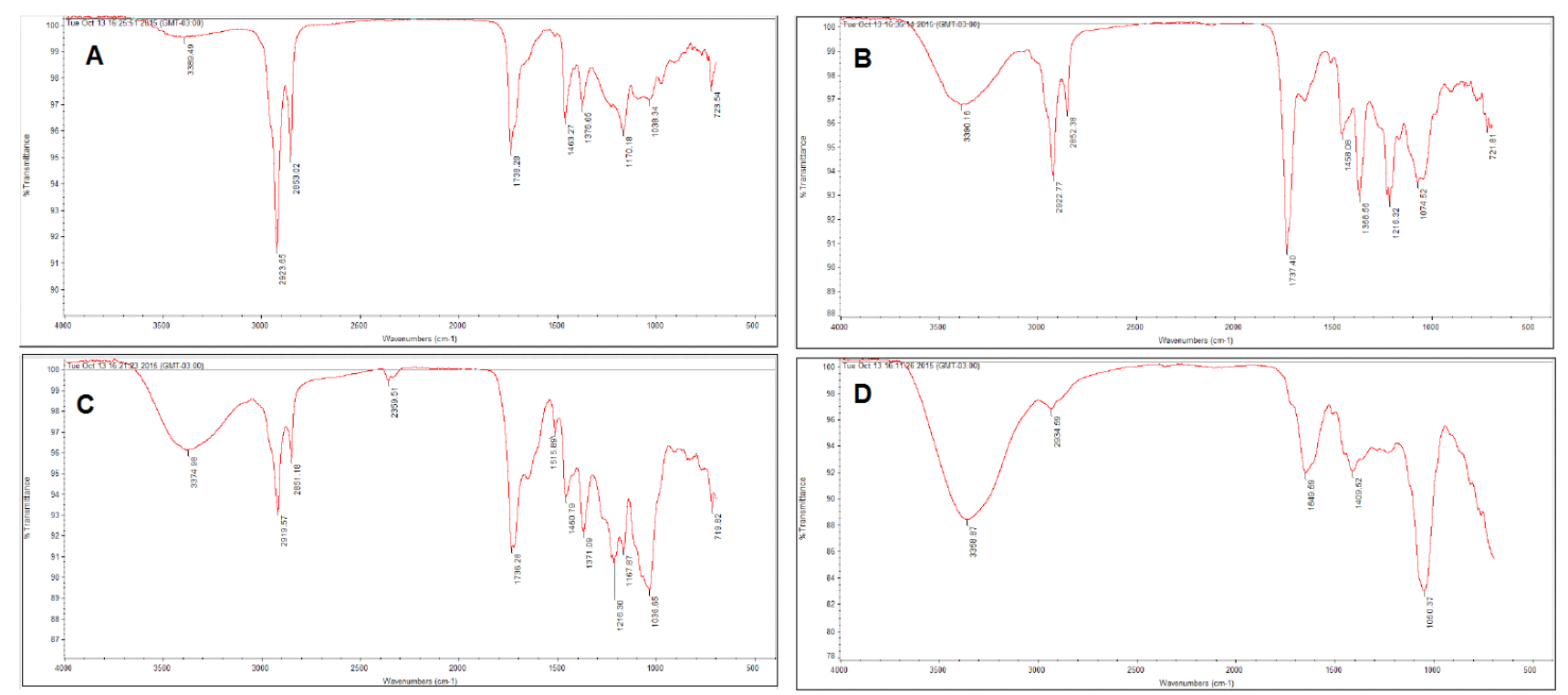

FIGURA 3. Espectro de absorção na região do infravermelho e as principais bandas e estiramentos das frações do cladódio pequeno.

Nota: Frações hexânica (A), clorofórmica (B), acetato de etila (C) e metanólica (D).

Fonte: Autora da pesquisa, 2015.

\section{Concentração de $100 \mathrm{ug} / \mathrm{mL}$ Cladódio Grande}
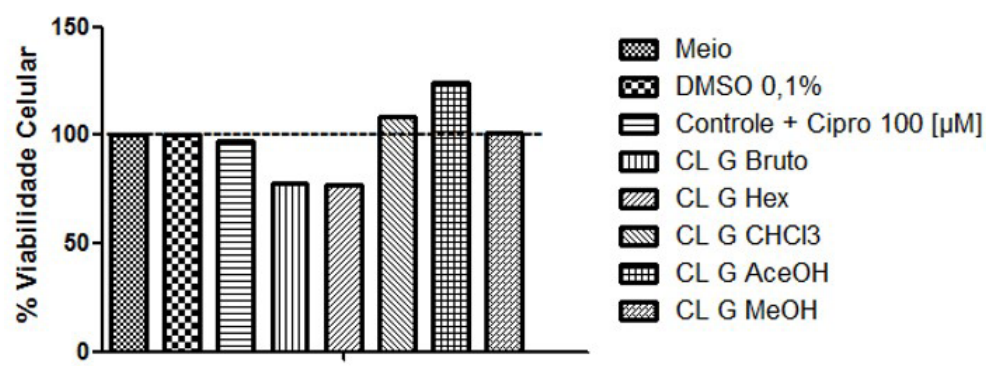

FIGURA 4. Porcentagem de viabilidade celular dos extratos etanólicos brutos e das frações do cladódio grande na concentração de $100 \mu \mathrm{g} / \mathrm{mL}$.

Nota: DMSO: dimetilsulfóxido; $\mu \mathrm{g} / \mathrm{mL}$ : microgramas por mililitros; +: positivo; $\mu \mathrm{M}$ : micromolar

Fonte: Autora da pesquisa, 2015.

\section{Concentração de 100 ug/mL Cladódio Pequeno}
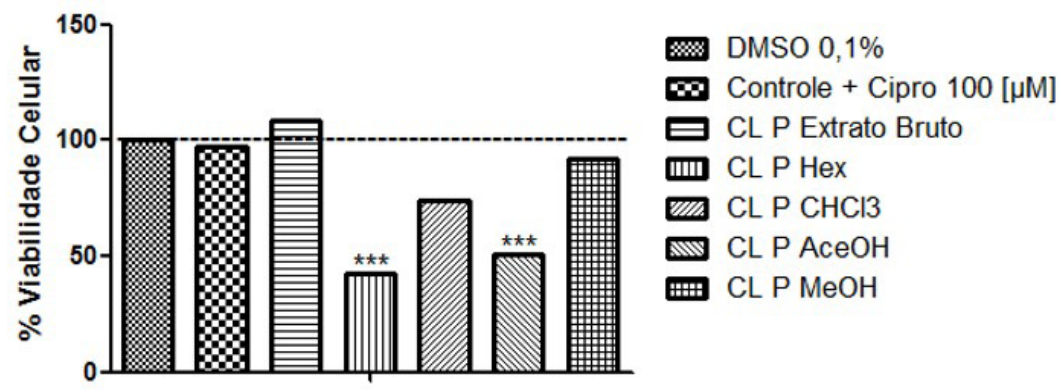

ख DMSO 0,1\%

Controle + Cipro $100[\mu \mathrm{M}]$

曰CL P Extrato Bruto

Iㅔ $C L P$ Hex

שa $\mathrm{CL} \mathrm{P} \mathrm{CHCl3}$

$\mathrm{CLPAceOH}$

요 $\mathrm{CL} \mathrm{P} \mathrm{MeOH}$

FIGURA 5. Porcentagem de viabilidade celular dos extratos etanólicos brutos e das frações do cladódio pequeno na concentração de $100 \mu \mathrm{g} / \mathrm{mL}$.

Nota: DMSO: dimetilsulfóxido; $\mu \mathrm{g} / \mathrm{mL}$ : microgramas por mililitros; +: positivo; $\mu \mathrm{M}$ : micromolar

Fonte: Autora da pesquisa, 2015.

Rev. Bras. PI. Med., Campinas, v.18, n.1, supl. I, p.307-315, 2016. 


\section{DISCUSSÃO}

As plantas medicinais são utilizadas por todos os grupos culturais há muito tempo. Os estudos químicos visam o descobrimento dos metabólitos presentes nas plantas, a exemplo os metabólitos secundários, os quais podem ser estudados no âmbito da química de produtos naturais e por vezes apresentam em sua composição substâncias que podem ser aplicadas nas áreas da farmácia e da biotecnologia (Matos, 2009).

Estudos com o gênero Opuntia remetem a presença de flavonoides, cumarinas, taninos, saponinas, esteroides e alcaloides confirmando assim os resultados obtidos através da prospecção, além de demonstrar outras classes químicas (Tomás et al., 2012; Astello-Garcia et al., 2015).

Os metabólitos secundários observados na prospecção fitoquímica foram confirmados na espectroscopia de IV onde o extrato bruto do cladódio grande da Opuntia cochenillifera (L.) Mill revelou (Ver figura 1A) uma banda larga em $3368 \mathrm{~cm}^{-1}$, que representa um estiramento axial de hidroxila $(\mathrm{O}-\mathrm{H})$ de álcool e, ainda, uma banda em $1044 \mathrm{~cm}^{-1}$ sugere a presença de ligações C-O. Presença de estiramento médio-forte em 2969 e $2922 \mathrm{~cm}^{-1}$ sugere a presença de alcanos $\left(\mathrm{C}_{\mathrm{n}} \mathrm{H}_{\mathrm{n}+2}\right)$ com carbono hibridizado $s p^{3}$ ligado a hidrogênio $\left(\mathrm{C}_{s p 3}-\mathrm{H}\right)$ na amostra. Um estiramento axial simétrico em $1738 \mathrm{~cm}^{-1}$ sugere ligações carbonilas $(C=O)$. A absorção na região de $1649 \mathrm{~cm}^{-1}$ sugere vibração axial de duplas ligações entre carbonos $(C=C)$, bem como, deformação assimétrica em $1367 \mathrm{~cm}$ ${ }^{1}$, cujo é indicativo de grupos metila $\left(\mathrm{CH}_{3}\right)$. Por fim, foi observado um estiramento fraco-médio assimétrico em 1216-1228 $\mathrm{cm}^{-1}$ referente à presença de grupamentos alquilamina (C-N) (Silverstain \& Webster, 2000).

Com relação ao extrato bruto cladódio pequeno da Opuntia cochenillifera (L.) Mill foi observado (Ver figura 1B) uma banda larga em $3357 \mathrm{~cm}^{-1}$ para hidroxila $(\mathrm{O}-\mathrm{H})$ de álcool. Presença de estiramento médio-forte em 2922 e $2852 \mathrm{~cm}^{-1}$ sugere a presença de alcanos $\left(\mathrm{C}_{n} \mathrm{H}_{n+2}\right)$ com carbono hibridizado $s p^{3}$ ligado a hidrogênio $\left(\mathrm{C}_{s p 3}-\mathrm{H}\right)$ na amostra. Estiramento axial simétrico em $1735 \mathrm{~cm}^{-1}$ sugere a presença de grupos carbonilas $(C=O)$. Em adição, vibração axial de duplas ligações entre carbonos $(C=C)$ em $1648 \mathrm{~cm}^{-1}$ e absorção de 1374 $\mathrm{cm}^{-1}$, que caracteriza presença de metila $\left(\mathrm{CH}_{3}\right)$. Por fim, a presença de um estiramento fraco-médio assimétrico em $1216 \mathrm{~cm}^{-1}$ refere-se à ocorrência de grupamentos alquilamina (C-N) (Silverstain \& Webster, 2000).

$\mathrm{Na}$ espectroscopia de IV das frações do cladódio grande, a fração hexânica (Ver figura 2A) apresentou estiramento axial forte de 2922-2852 $\mathrm{cm}^{-1}$, sugestivo de alcanos $\left(\mathrm{C}_{\mathrm{n}} \mathrm{H}_{\mathrm{n}+2}\right)$ na amostra; banda larga em $1714 \mathrm{~cm}^{-1}$ para $\mathrm{C}=\mathrm{O}$; estiramento fraco-médio em $1378 \mathrm{~cm}^{-1}$ para metila $\left(\mathrm{CH}_{3}\right)$ e por fim, banda em $1050 \mathrm{~cm}^{-1}$ para C-O. Na fração de clorofórmio (Ver figura 2B) foi possível observar banda larga em $3380 \mathrm{~cm}^{-1}$ para hidroxila $(\mathrm{O}-\mathrm{H})$; estiramento axial médio em $1739 \mathrm{~cm}^{-1}$ para carbonila $(C=O)$; estiramento assimétrico em $1640 \mathrm{~cm}^{-1}$ para $\mathrm{C}=\mathrm{C}$ e estiramento axial forte em $1365 \mathrm{~cm}^{-1}$ para metila $\left(\mathrm{CH}_{3}\right)$; estiramento fraco-médio em $1216 \mathrm{~cm}^{-1}$ para alquilamina (C-N); por fim, banda em $1044 \mathrm{~cm}^{-1}$ para C-O. Na fração de acetato de etila (Ver figura 2C) houve banda larga em $3375 \mathrm{~cm}^{-1}$ para hidroxila (O-H); estiramento axial forte em $2924-2852 \mathrm{~cm}^{-1}$ para alcanos $\left(\mathrm{C}_{\mathrm{n}} \mathrm{H}_{\mathrm{n}+2}\right)$; estiramento assimétrico em $1716 \mathrm{~cm}^{-1}$ para carbonila $(\mathrm{C}=\mathrm{O})$; estiramento axial forte em $1376 \mathrm{~cm}^{-1}$ para metila $\left(\mathrm{CH}_{3}\right)$, por fim, banda em $1046 \mathrm{~cm}^{-1}$ para C-O. Na fração metanólica (Ver figura 2D) foi possível observar banda larga em 3396 $\mathrm{cm}^{-1}$ para hidroxila $(\mathrm{O}-\mathrm{H})$; estiramento assimétrico em $1637 \mathrm{~cm}^{-1}$ para $\mathrm{C}=\mathrm{C}$ e estiramento axial forte em $1358 \mathrm{~cm}^{-1}$ para metila $\left(\mathrm{CH}_{3}\right)$, por fim, banda em $1044 \mathrm{~cm}^{-1}$ para C-O (Silverstain \& Webster, 2000).

Já para as frações do cladódio pequeno, na fração de hexano (Ver figura $3 A$ ) houve um estiramento axial forte de $2923-2853 \mathrm{~cm}^{-1}$, sugestivo de alcanos $\left(\mathrm{C}_{\mathrm{n}} \mathrm{H}_{\mathrm{n}+2}\right)$; banda larga em $1738 \mathrm{~cm}^{-1}$ para $\mathrm{C}=\mathrm{O}$; estiramento fraco-médio em $1376 \mathrm{~cm}^{-1}$ para metila $\left(\mathrm{CH}_{3}\right)$; e por fim, banda em $1038 \mathrm{~cm}^{-1}$ para C-O. Na fração de clorofórmio (Ver figura 3B) houve a presença de uma banda larga em 3390 $\mathrm{cm}^{-1}$ para hidroxila $(\mathrm{O}-\mathrm{H})$; estiramento axial forte em 2922-2852 $\mathrm{cm}^{-1}$ para alcanos $\left(\mathrm{C}_{\mathrm{n}} \mathrm{H}_{\mathrm{n}+2}\right)$; estiramento axial médio em $1737 \mathrm{~cm}^{-1}$ para carbonila $(\mathrm{C}=\mathrm{O})$; estiramento axial forte em $1368 \mathrm{~cm}^{-1}$ para metila $\left(\mathrm{CH}_{3}\right)$, estiramento fraco-médio em $1216 \mathrm{~cm}^{-1}$ para alquilamina (C-N); por fim, banda em $1044 \mathrm{~cm}^{-1}$ para C-O. Na fração de acetato de etila (Ver figura 3C) foi possível observar uma banda larga em 3364 $\mathrm{cm}^{-1}$ para hidroxila $(\mathrm{O}-\mathrm{H})$; estiramento axial forte em 2919-2851 $\mathrm{cm}^{-1}$ para alcanos $\left(\mathrm{C}_{\mathrm{n}} \mathrm{H}_{\mathrm{n}+2}\right)$; estiramento assimétrico em $1736 \mathrm{~cm}^{-1}$ para carbonila $(\mathrm{C}=\mathrm{O})$; estiramento axial forte em $1371 \mathrm{~cm}^{-1}$ para metila $\left(\mathrm{CH}_{3}\right)$; estiramento fraco-médio em $1216 \mathrm{~cm}^{-1}$ para alquilamina (C-N); por fim, banda em $1036 \mathrm{~cm}^{-1}$ para C-O. Na fração metanólica (Ver figura 3D), observou-se uma banda larga em $3358 \mathrm{~cm}^{-1}$ para hidroxila (O-H); estiramento assimétrico em 1649 $\mathrm{cm}^{-1}$ para $\mathrm{C}=\mathrm{C}$; por fim, banda em $1050 \mathrm{~cm}^{-1}$ para C-O (Silverstain \& Webster, 2000).

Sobre a atividade antioxidante, os estudos demonstram a atividade no gênero Opuntia (Semedo 2012; Madrigal-Santillán et al., 2013; Butera et al., 2002), no entanto no presente estudo, a espécie não apresentou atividade antioxidante, corroborando com dados encontrados na literatura referente ao estudo de Souza et al. (2014). Mesmo que comprovada a existência de fenóis em uma

Rev. Bras. PI. Med., Campinas, v.18, n.1, supl. I, p.307-315, 2016. 
quantidade moderada, outros compostos podem ter mascarado os compostos fenólicos, fazendo com que a atividade não fosse identificada.

O extrato etanólico bruto, bem como suas frações não apresentaram toxicidade na concentração de $100 \mu \mathrm{g} / \mathrm{mL}$. Já no cladódio pequeno, apenas as frações de hexano e em acetato de etila apresentaram citotoxicidade, o que pode indicar a presença de metabólitos tóxicos nessas frações.

A ausência de atividade antibacteriana nos extratos e frações da espécie estudada tem sido atestada em outros estudos encontrados na literatura com o gênero (Soares, 2012; Souza et al., 2014). Mesmo com a presença de flavonoides, ao qual é sugestiva a atividade microbicida (Parcker \& Luz, 2007), os extratos e frações não conseguiram inibir o crescimento bacteriano.

Os resultados obtidos podem ser relacionados ao fenótipo da planta, pois se sabe que as características das espécies e suas constituições químicas irão variar de acordo com a sua origem, visto que as espécies encontradas na região Nordeste têm características advindas das espécies da América do Norte e as espécies que se encontram na região sul, possuem características das espécies oriundas da América do Sul (Barroso et al., 1978), podendo influenciar nas atividades biológicas da planta.

Estudos que visem o isolamento dos compostos encontrados, buscando um melhor aproveitamento dos mesmos e a realização de novos testes voltados a outras atividades biológicas, podem propor novas perspectivas frente ao uso da espécie vegetal no desenvolvimento de produtos voltados para as áreas da saúde e da biotecnologia.

\section{AGRADECIMENTOS}

À botânica Rosangela Pereira de Lyra Lemos pela identificação botânica do material vegetal. À Profa ${ }^{\text {. Dr }}{ }^{a}$. Camila Braga Dornelas e à MSc. Tamires Andrade da Silva do Laboratório de Tecnologia de Nanosistemas Carreadores de Substâncias Ativas (TecNano). Às agências colaboradoras Fundação de Amparo à Pesquisa do Estado de Alagoas (FAPEAL), Conselho Nacional de Desenvolvimento Científico e Tecnológico (CNPq) e a Coordenação de Aperfeiçoamento de Pessoal de Nível Superior (CAPES).

\section{REFERÊNCIAS}

AMMAR, I. et al. Antioxidant,antibacterial and in vivo dermal wound healing effects of Opuntia flower extracts. International Journal of Biological Macromolecules. v.81, p. 483-490, 2015.
ANDRADE, C.T.S; MARQUES, J.G.W; ZAPPI, D.C. Utilização de cactáceas por sertanejos baianos. Revista Brasileira de Plantas Medicinais, v.8, n.3, p.36-42, 2006.

ARAUZA, J.C.G. Efectos biofuncionales Del Nopal y la Tuna. Horticultural Reviews.v.71,p.1-9, 2009.

ASTELLO-GARCIA, M.G et al. Chemical composition ad phenolic compounds profile of cladodes from Opuntia spp. Cultivars with different domestication gradient. Journal of Food Composition and Analysis. v.43, p.119-130, 2015.

BALUNAS, M.J; KINGHORN, D. Drug discovery from medicinal plants. Life Sciences. v.78, p. 431-41. 2005.

BARBERA, G; INGLESE, P; BARRIOS, E. Agroecología, cultivos y usos del nopal. Estudio FAO producción y protección vegetal, 132, Roma: FAO, 1999. 250p.

BARROSO GM; PEIXOTO AL; COSTA CG; ICHASO CLF; GUIMARÃES EF; LIMA HC. Sistemática de angiospermas do Brasil. 1 ed. Rio de Janeiro: Livros Técnicos e Científicos Editora S.A, 1978. 255p.

BRAND-WILLIAMS W; et al., Use of a free radical method evaluate antioxidant activity. Food Science and Technology, v. 28, p.25-30, 1995.

BUTERA, D. et al. Antioxidant activities of sicilian prickly pear (Opuntia ficus indica) fruit extracts and reducing properties of its betalains: betanin and indicaxanthin. Journal of Agricultural and Food Chemistry. v. 50, n.23, p.6895-6901, 2002.

CHIACCHIO, F.P.B. et al. Palma forrageira: uma oportunidade econômica ainda desperdiçada para o semi-árido. Revista Bahia Agrícola., v.7, n.3, p.3949, 2006.

CLSI, Performance standards for antimicrobial susceptibility testing: twenty-second informational supplement. CLSI document M100-S22. Wayne, PA: Clinical and Laboratory Standards Institute; 2012.

GALATI, E.M; et al. Effect of Opuntia ficus indica (L.) Mill. cladodes in the wound healing process. Journal of the Professional Association for Cactus Development. v. 5, p.1-16, 2003.

GOMES, F.S.L; CARVALHO, D.V. Tratamento de ferida: revisão da literatura. Revista Mineira de Enfermagem, v.6, n.1, p.67-72, 2002.

GUERREIRO, W; ANDRADE, C.T; MARQUES, J.G. Um estudo de caso da conexão Homem/vegetal (Cactaceae/ Bromeliaceae), no Semi-árido Alagoano. In: SIMPÓSIO BRASILEIRO DE ETNOBIOLOGIA E ETNOECOLOGIA, 3., 2000, Piracicaba, SP. Resumos... Piracicaba, SP, 2000. p. 68.

HAHM, S.W. et al. Opuntia Humifusa Partitioned Extracts Inhibit the Growth of U87mg Human Glioblastoma Cells. Plant Foods for Human Nutrition, v. 65 , n. 3 , p. 247-52, 2010.

LEWINSOHON, T.M.; PRADO, P.I. Biodiversidade Brasileira: Síntese do Estado Atual do Conhecimento. 1 ed, Editora Contexto, SP. 2003. 176p.

LEWIS, W.; Memory ELVIN-LEWIS P.F. Medical botany: Plants affecting man's health. 2 ed. New York: Willey, 2003. 832p.

MADRIGAL-SANTILLÁN, E. et al. Antioxidant and Anticlastogenic Capacity of Prickly Pear Juice. Nutrients, v. 5, p.4145-4158, 2013.

MATOS, F.J.A. Introdução à Fitoquímica Experimental.

Rev. Bras. PI. Med., Campinas, v.18, n.1, supl. I, p.307-315, 2016. 
3 ed. Ed. da UFC, Fortaleza, Ceará, 2009, 148p.

NUNES, C.S. Uso e aplicações da palma forrageira como uma grande fonte de economia para o semiárido nordestino. Revista Vede de Agroecologia e Desenvolvimento Sustentável, v.6, n.1, p. 58-66, 2011.

PACE, D; et al. Efeito de substâncias antioxidantes (vitamina c, vitamina e e gingko biloba) na viabilidade de retalho cutâneo dorsal em ratos. Revista Brasileira de Cirurgia Plástica. v.21, n.2, p. 77-81, 2006.

PARCKER, J.F; LUZ, M.M.S. Método para avaliação e pesquisa da atividade antimicrobiana de produtos de origem natural. Revista Brasileira de Farmacognosia. v.17, n.1,p. 639-644, 2007.

PARK, E.H; CHUN, M.J. Wound healing of Opuntia ficus indica. Fitoterapia. v.72, p.165-167, 2001.

POEJO, J.M.A. Evaluation of Opuntia spp. bioactive products as promising natural chemotherapeutical agents - an in vitro approach. 2011. 64p. Dissertação de Mestrado (Biotecnologia), Universidade Nova de Lisboa, Lisboa.

SANTOS, N. A resistência bacteriana no contexto da infecção hospitalar. Texto \& Contexto Enfermagem. v. 13, p. 64-70, 2004.

SEMEDO, A.C.J. Compostos bioativos de Opuntia ficus indica. 2012. 119p. Dissertação (Mestrado em Farmácia), Universidade de Lisboa, Lisboa.

SILVERSTAIN, R.M; WEBSTER, F.X. Identificação espectrométrica de compostos orgânicos. 6 ed. Rio de Janeiro: LTC; 2000, 506p.

SOARES, B.S.A. Obtenção e caracterização do extrato nebulizado da opuntia ficus-indica (L.) Mill e avaliação da sua atividade antimicrobiana e fotoproterora. 2012. 24p.Trabalho de Graduação de Curso (Farmácia), Universidade Estadual da Paraíba, João Pessoa.

SOUZA, C. M.P. et al. Characterization of atomized extract of Opuntia ficus-indica (L.) Mill. and assessment of its pharmaceutical potential. Revista de Ciências Farmacêuticas Básica e Aplicada. v. 35, n. 2, p. 195203, 2014.

TAYLOR, N.P; ZAPPI, D. Distribuição das espécies de Cactaceae na caatinga In: Vegetação e flora das caatingas. SAMPAIO, E.V.S.B.; GIULIETTI, A.M.; VIRGINIO, J.; GAMARRA-ROJAS, C.F.L. 1 ed. Recife: Associação Plantas do Nordeste; Centro Nordestino de Informação sobre Plantas, 2002, p.123-125.

TOMÁS, C.G. et al. Estudio químico y fitoquímico de la Opuntia ficus-indica "tuna", y elaboración de un alimento funcional. Revista Peruana de Química e Ingeniería Química. v. 15, n. 1, p.70-74, 2012.

TROMBETTA, D. et al. Effect of polysaccharides from Opuntia ficus-indica (L.) cladodes on the healing of dermal wounds in the rat. Phytomedicine, n.13, p. 352-358, 2006.

ZOU, D.M. et al. Cactus Pear: A Natural Product in Cancer Chemoprevention. Nutrition Journal, v.4, n. 25, 2005.

Rev. Bras. PI. Med., Campinas, v.18, n.1, supl. I, p.307-315, 2016. 